\title{
Airway epithelium-shifted mast cell infiltration regulates asthmatic inflammation via IL-33 signaling
}

\author{
Matthew C. Altman, ${ }^{1}$ Ying Lai, ${ }^{2}$ James D. Nolin, ${ }^{2}$ Sydney Long, ${ }^{1}$ Chien-Chang Chen, ${ }^{2}$ Adrian M. Piliponsky, ${ }^{3}$ William A. Altemeier, ${ }^{2}$ \\ Megan Larmore, ${ }^{4}$ Charles W. Frevert, ${ }^{4}$ Michael S. Mulligan, ${ }^{5}$ Steven F. Ziegler, ${ }^{6}$ Jason S. Debley, ${ }^{3,7}$ Michael C. Peters, ${ }^{8}$ \\ and Teal S. Hallstrand ${ }^{2}$ \\ 'Division of Allergy and Infectious Diseases and 'Division of Pulmonary, Critical Care and Sleep Medicine, Department of Medicine, University of Washington, Seattle, Washington, USA. ${ }^{3}$ Center for Immunity \\ and Immunotherapies, Seattle Children's Research Institute, Seattle, Washington, USA. ${ }^{4}$ Department of Comparative Medicine, University of Washington, Seattle, Washington, USA. ${ }^{5}$ Division of Cardiothoracic \\ Surgery, Department of Surgery, University of Washington, Seattle, Washington, USA. IImmunology Program, Benaroya Research Institute, Seattle, Washington, USA. 'Division of Pulmonary and Sleep Medicine, \\ Department of Pediatrics, University of Washington, Seattle, Washington, USA. ${ }^{8}$ Division of Pulmonary, Critical Care, Allergy and Sleep Medicine, Department of Medicine, UCSF, San Francisco, California, USA.
}

\begin{abstract}
Asthma is a heterogeneous syndrome that has been subdivided into physiologic phenotypes and molecular endotypes. The most specific phenotypic manifestation of asthma is indirect airway hyperresponsiveness (AHR), and a prominent molecular endotype is the presence of type 2 inflammation. The underlying basis for type 2 inflammation and its relationship to AHR are incompletely understood. We assessed the expression of type 2 cytokines in the airways of subjects with and without asthma who were extensively characterized for AHR. Using quantitative morphometry of the airway wall, we identified a shift in mast cells from the submucosa to the airway epithelium specifically associated with both type 2 inflammation and indirect AHR. Using ex vivo modeling of primary airway epithelial cells in organotypic coculture with mast cells, we show that epithelialderived IL-33 uniquely induced type 2 cytokines in mast cells, which regulated the expression of epithelial IL33 in a feedforward loop. This feed-forward loop was accentuated in epithelial cells derived from subjects with asthma. These results demonstrate that type 2 inflammation and indirect AHR in asthma are related to a shift in mast cell infiltration to the airway epithelium, and that mast cells cooperate with epithelial cells through IL-33 signaling to regulate type 2 inflammation.
\end{abstract}

\section{Introduction}

Asthma is a heterogeneous disorder with features of airway inflammation, reversible airflow obstruction, and airway hyperresponsiveness (AHR). Indirect AHR is a particularly important pathophysiologic finding because it is a highly specific feature of asthma not seen in other diseases $(1,2)$, and because it is associated with the persistence of asthma (3). In contrast to direct AHR, in which an exogenous stimulus for bronchoconstriction is administered, indirect AHR is the result of the endogenous release of mediators from the airways. Direct AHR is present in other airway disorders and is related to changes in the airway smooth muscle (4), as well as baseline lung function and airway geometry (1). Despite the specificity of indirect AHR, the basis of this fundamental aspect of asthma is incompletely understood. Indirect AHR can be measured by tests such as the dry air exercise challenge test to assess exercise-induced bronchoconstriction (EIB), as well as osmotic challenge tests (2). Indirect AHR occurs across all levels of asthma severity, and is not related to baseline lung function (5). There is a general link between airway inflammation and indirect AHR, but the basis of this association is incompletely understood.

Conflict of interest: The authors have declared that no conflict of interest exists. Copyright: () 2019, American Society for Clinical Investigation.

Submitted: November 26, 2018; Accepted: August 7, 2019; Published: October 7, 2019. Reference information: J Clin Invest. 2019;129(11):4979-4991.

https://doi.org/10.1172/JCl126402.
To better understand the basis for specific manifestations of asthma, the concept of molecular endotypes has been developed. The link between a molecular endotype and physical phenotype is critical because of the important implications for tailoring asthma therapy for a specific manifestation of asthma, and for developing novel targets that can lead to more specific and effective therapies. A major molecular endotype found in some individuals with asthma is "Th2-high," originally defined by the expression of genes in the epithelium that reflect the effects of IL-13 (6). In human studies, the expression of these IL-13-induced genes in the airway epithelium was also accompanied by the expression of mast cell granule proteins, suggesting a link between mast cells and Th2high asthma. Previous work has also shown that immunostaining for the Th2-type cytokine IL-4 can be localized to mast cells and eosinophils in the airways (7). In a genome-wide expression study of airway cells, we found that mast cell genes were higher in subjects with indirect AHR, suggesting an endotype-phenotype association (8). Subsequent work showed that the expression of selected mast cell genes in the epithelium and the number of epithelial mast cells were higher in subjects with greater indirect AHR (9). Although these studies suggest a relationship between type 2 inflammation and indirect AHR, this association has not been thoroughly investigated in humans. Furthermore, the mechanisms by which mast cells interact with the epithelium to regulate type 2 inflammation are incompletely understood.

Recent studies have revealed that cytokines such as IL-25, IL-33, and thymic stromal lymphopoietin (TSLP) that are highly 
expressed in the airway epithelium are implicated in human asthma by genome-wide association studies (10). Furthermore, models of asthma indicate that these cytokines serve as key central regulators of type 2-polarized inflammation (11-14), and that innate cells, including recruited macrophages, type 2 innate lymphoid cells (ILC2s), and mast cells, are targets of these epithelial derived cytokines. Several recent studies have identified alterations in the number of recruited macrophages and ILC2s in asthma (15-19), but the potential role of mast cells has received less attention. Animal models using inhaled antigens suggest that mast cells play a key role in the development of experimental asthma (20-22), but the possibility that mast cells act as central regulators of type 2 inflammation has not previously been shown.

Using a recently developed metric of type 2 inflammation in the airways (23), we examined the expression of type 2 cytokines in a cohort of subjects with and without asthma who were extensively characterized for features of AHR. Although type 2 inflammation persists to varying degrees in many individuals treated with inhaled or systemic corticosteroids (24-28), type 2 inflammation is often steroid responsive $(4,29,30)$; therefore, the present study was specifically conducted in subjects who were not using any corticosteroid or other immune-modulating therapies at the time of sample collection and phenotypic characterization. We used quantitative morphometry in the form of design-based stereology to provide an unbiased assessment of the density of mast cells, and specifically assessed the number of these cells relative to the surface area of the basal lamina in each compartment as well as the volume density of these cells in the epithelial and submucosal compartments $(31,32)$. These results revealed two novel observations. First, submucosal mast cells, which were abundant in healthy controls, are shifted from the submucosal compartment to the epithelium in asthma, and this shift is strongly associated with type 2 inflammation. Second, the physical phenotype that was most closely associated with type 2 inflammation was indirect AHR. Based on these findings, we used an ex vivo model of primary airway epithelial cells in organotypic coculture with mast cells, leading to the identification of a mast cell-dependent feed-forward loop mediated through IL-33, in which IL-33-activated mast cells increase the expression of epithelial IL33, which in turn serves as a unique signal upregulating the production of type 2 cytokines in mast cells. This feed-forward loop is dependent on mast cells but is not a consequence of IL-13 signaling. Using primary airway epithelial cells from children with and without asthma, we found that the amplification of epithelial IL33 expression by IL-33-primed mast cells is accentuated in epithelial cells from children with asthma. These results provide clear evidence implicating a shift in the location of mast cells to the epithelium in humans and identify intraepithelial mast cells as regulators of type 2 inflammation and airway dysfunction in asthma.

\section{Results}

Individuals with indirect AHR in asthma have a higher type 2 gene signature in sputum cells. In previous work, the combined expression of $I L 4, I L 5$, and $I L 13$ in induced sputum cells was demonstrated to classify subjects into Th2-high and Th2-low subtypes, providing a minimally invasive means of assessing this key molecular endotype (23). Here we used this approach to examine the relationships between type 2 inflammation, airway physiology, and histologic manifestations of asthma using a cohort of subjects with asthma and without (healthy controls). Subjects were extensively characterized both phenotypically and for tissue infiltration with mast cells. Samples and pulmonary function data were collected in the absence of corticosteroid or other immune-modulating therapies (Supplemental Table 1; supplemental material available online with this article; https://doi.org/10.1172/JCI126402DS1).

RNA of sufficient quantity and quality from the induced sputum cell pellet was available from a total of 33 subjects, including 25 subjects with asthma. To assess type 2 gene expression in this cohort, the expression levels of IL4, IL5, and IL13 were centered, scaled, and combined into the summary type 2 gene mean (T2GM) metric (23). Subjects were classified as "type 2-high" if the T2GM value was 2 standard deviations from the mean of the healthy control population in the present population. Overall, the T2GM did not significantly differ between healthy controls and subjects with asthma $(P=0.12)$. Substantial heterogeneity was observed in this metric in subjects with asthma, with 14 of the 25 subjects with asthma (56\%) being classified as type 2-high (T2-high). In contrast, none of the healthy controls were classified as T2-high. AHR to methacholine was present in all of the subjects with asthma but not in the healthy controls (Supplemental Figure 1A). However, there was significant phenotypic variability in the response to dry air exercise challenge, which resulted in significant airway narrowing ( $>10 \%)$ in $57 \%$ of the asthma population (classified as $\mathrm{EIB}^{+}$) (Supplemental Figure 1B). Although these 2 measures of asthma were well correlated, there was a substantial range of response with both aspects of AHR (Supplemental Figure $1 C)$. We found that the T2GM varied by asthma phenotype; specifically, the $\mathrm{EIB}^{+}$asthma group had a higher T2GM than both the healthy controls $(P=0.04)$ and the $\mathrm{EIB}^{-}$asthma group $(P=0.04$; Figure $1 \mathrm{~A})$. The scaled expression of $I L 5$ was highest in the $\mathrm{EIB}^{+}$ asthma group relative to both the healthy controls $(P=0.02)$ and the $\mathrm{EIB}^{-}$asthma group $(P=0.02$; Figure $1 \mathrm{~B})$. The scaled expression of $I L 4$ trended toward higher in the $\mathrm{EIB}^{+}$group relative to the $\mathrm{EIB}^{-}$ group ( $P=0.07$; Supplemental Figure $2 \mathrm{~A}$ ), while the expression of IL13 was higher in the $\mathrm{EIB}^{+}$group relative to the healthy controls $(P=0.03$; Supplemental Figure 2B). In contrast to the expression of the type 2 cytokines, the expression of the type 1 cytokine IFN- $\gamma$ (IFNG; Supplemental Figure 2C) and arginase 2 (ARG2; Supplemental Figure 2D) was not different in either asthma phenotype. Of the type 2 cytokines, the T2GM was most highly correlated with the expression of IL13 $\left(r^{2}=0.87, P<0.0001\right.$; Figure 1C) and was also highly correlated with the expression of IL5 $\left(r^{2}=0.84, P\right.$ $<0.0001)$, but was less correlated with $I L 4\left(r^{2}=0.75, P<0.0001\right)$, suggesting that IL13 and IL5 are the dominant parameters determining the observed relationships with the T2GM. These results indicate that type 2 inflammation is common but not universally present among subjects with asthma even in the absence of controller therapies, and suggest that the T2-high endotype is related to indirect AHR manifested by EIB.

The T2GM in the airways is associated with airflow obstruction and indirect AHR in human asthma. The relationship between type 2 inflammation and airway physiology is not well established. Therefore, we sought to understand the relationship between type 2 inflammation measured by the T2GM and detailed mea- 
A

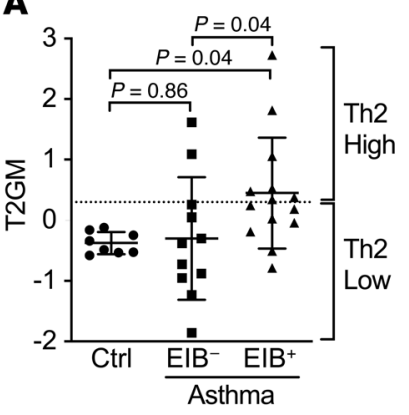

B

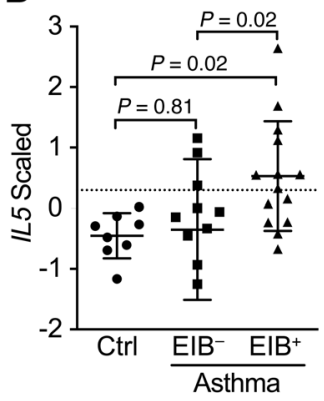

C

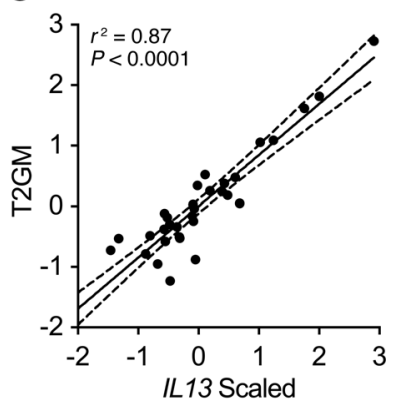

Figure 1. Type 2 gene expression in induced sputum is specifically elevated in ElB ${ }^{+}$asthma. (A) The T2CM was elevated in ElB' asthma subjects $(n=14)$ compared with ElB- asthma subjects $(n=11)$ and healthy controls $(n=8)$. (B) Of the 3 type 2 genes, expression of IL5 showed the most significant difference among the groups. Shown are means and SDs. Analyses are by 1-way ANOVA with correction for multiple comparisons. (C) IL13 expression was most highly associated with the T2GM by linear regression ( $95 \%$ confidence intervals are shown).

surements of lung function and AHR in this cohort. We found that there was no clear relationship with baseline lung function measured by the forced expiratory volume in 1 second $\left(\mathrm{FEV}_{1}\right)$ percent predicted (\% predicted) $\left(r^{2}=0.08, P=0.12\right.$; Figure 2A) or the forced vital capacity (FVC) \% predicted $\left(r^{2}=0.05, P=0.22\right)$. However, the T2GM was significantly associated with airflow obstruction reflected in the $\mathrm{FEV}_{1} / \mathrm{FVC}$ ratio $\left(r^{2}=0.22, P=0.006\right.$; Figure $2 \mathrm{~B}$ ), and restricting the analysis to subjects with asthma showed the same relationship between T2GM and $\mathrm{FEV}_{1} / \mathrm{FVC}$ ratio $\left(r^{2}=\right.$ $0.20, P=0.03$ ) but neither the $\mathrm{FEV}_{1}$ nor FVC \% predicted. Direct AHR measured by methacholine challenge was close to a significant association with the T2GM in the full population $\left(r^{2}=0.10\right.$, $P=0.07$; Figure $2 \mathrm{C}$ ), but not when restricted to the subjects with asthma $\left(r^{2}=0.07, P=0.21\right)$. In contrast, across the full population, there was a significant association between the T2GM and the severity of indirect AHR measured by the maximum fall in $\mathrm{FEV}_{1}$ after dry air exercise challenge $\left(r^{2}=0.27, P=0.002\right)$ and in the area under the $\mathrm{FEV}_{1}$-time curve in the first 30 minutes after exercise (AUC30; $r^{2}=0.28, P=0.002$; Figure 2D). This relationship between the T2GM and indirect AHR remained when the analysis was restricted to the subjects with asthma (AUC30, $r^{2}=0.25, P=$ 0.01). Examining these same associations with each of the T2GM cytokines individually demonstrates that both $\mathrm{FEV}_{1} / \mathrm{FVC}$ and severity of EIB (AUC30) were associated most strongly with IL13 expression, and secondarily with IL5 expression, but less so with IL4 expression (Supplemental Table 2).

These results demonstrate that type 2 inflammation reflected in the T2GM is most closely associated with the degree of indirect AHR.

The T2GM in the airways is significantly related to the expression of certain mast cell genes in the airways. Mast cells with a unique pattern of expression of proteases were identified in asthma, and the mast cell genes tryptase (TPSAB1) and carboxypeptidase A3 (CPA3) but not chymase (CMA1) were found to be increased in subjects with EIB (Supplemental Figure 3, A-C), consistent with previous work $(8,9)$. Here we assessed the relationship between these mast cell genes and a direct measure of type 2 gene expression in the airways. We found that the T2GM was highly correlated with the expression of TPSAB1 $\left(r^{2}=0.46, P<0.0001\right.$; Figure $\left.3 \mathrm{~A}\right)$ relationship between the T2GM and the severity of indirect AHR, we found that the severity of EIB measured by the AUC30 was also associated with TPSAB1 $\left(r^{2}=0.22, P\right.$ $=0.006$; Supplemental Figure 3D $)$ and $C P A 3\left(r^{2}=0.31, P=0.0007\right.$; Supplemental Figure 3E) in induced sputum cells and not with CMA1 $\left(r^{2}=0.00, P=0.82\right.$; Supplemental Figure $\left.3 \mathrm{~F}\right)$. These results identify a close association between type 2 inflammation and the expression of a specific set of mast cell genes in airway cells and the airway epithelium, confirming the close relationship between mast cell gene expression in the airways and type 2 inflammation.
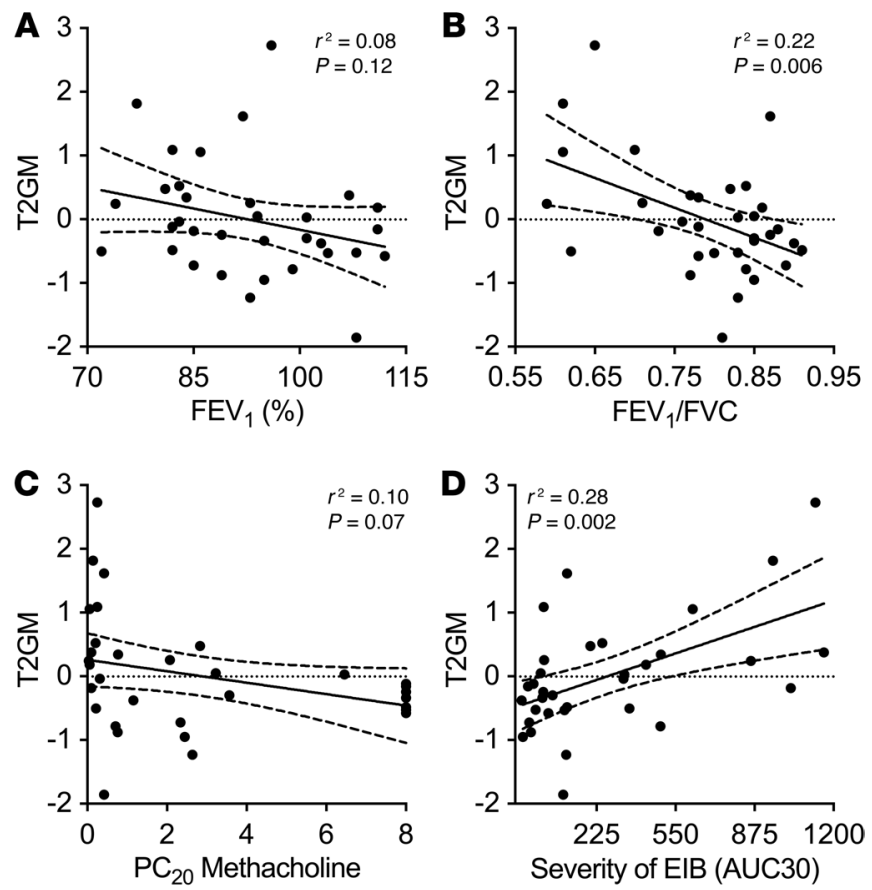

Figure 2. Sputum type 2 gene expression correlates with airway obstruction and the severity of indirect AHR. (A and B) The T2GM did not correlate with $\mathrm{FEV}_{1} \%$ predicted (A) but did correlate with the $\mathrm{FEV}_{1} / \mathrm{FVC}$ ratio (B). (C and D) The T2GM trended toward an association with severity of direct AHR (C) and was significant in association with indirect AHR (D). Associations were assessed by linear regression; shown are regression lines and $95 \%$ confidence intervals. 
Induced sputum cells
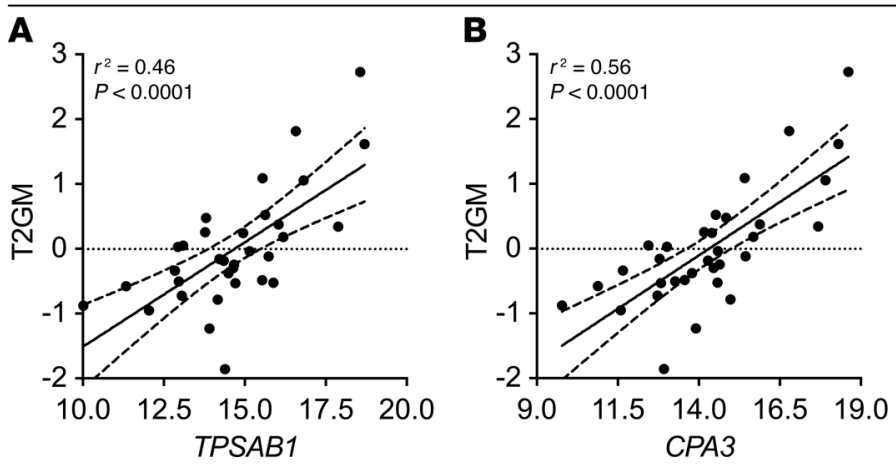

Epithelial brushings
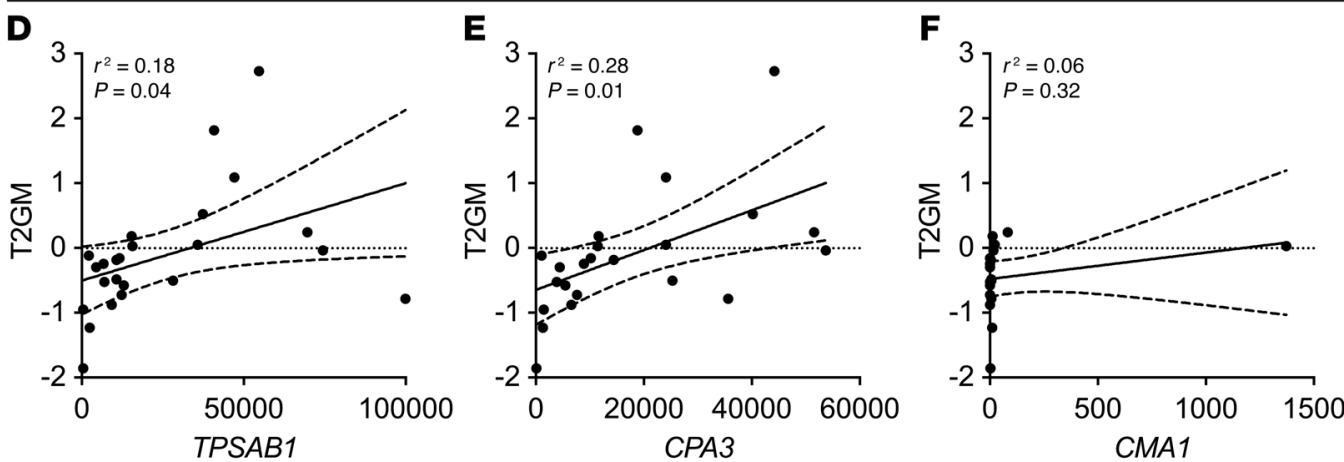

Figure 3. Sputum type 2 gene expression is associated with mast cell gene expression in sputum and bronchial brushings. The T2GM expression in sputum was significantly correlated with the expression of the mast cell genes TPSAB1 and $C P A 3$, but not $C M A 1$, in induced sputum cells (A-C) and also in bronchial epithelial brushing (D-F). All associations are by linear regression; shown are regression lines and 95\% confidence bounds.
A shift in mast cells from the submucosal to the epithelial compartment occurs in association with indirect AHR. We used quantitative morphometry in the form of design-based stereology on endobronchial biopsies to further delineate the density of mast cells in different tissue compartments. We used 2 complementary stereology approaches to quantify the location of mast cells in the airway wall. For the primary analysis, we quantified the number of mast cells relative to the reference surface area of the basal lamina to provide an assessment of the number mast cells above or below the basal lamina. For the second analysis, we used the physical dissector to assess the density of mast cells in each reference space of the epithelial volume, and the submucosal volume (see an illustrated presentation of these methods in Supplemental Figure 4). These complementary unbiased assessments were designed to determine whether there is a specific shift in the location of mast cells in asthma from below the basal lamina in the submucosa to the epithelial compartment. The quantity of mast cells in the epithelium relative to the surface area of basal lamina was increased in asthma $(P=0.02$; Figure $4 \mathrm{~A})$. This difference was driven by the $\mathrm{EIB}^{+}$asthma group, which had more intraepithelial mast cells per surface area of the basal lamina than both the $\mathrm{EIB}^{-}$asthma group $(P=0.02)$ and the healthy controls $(P=0.002$; Figure $4 \mathrm{~B})$. The $\mathrm{EIB}^{-}$group did not differ from the healthy control group $(P=$ 0.47). An association between the severity of EIB measured by the AUC30 and the quantity of mast cells in the epithelium relative to the surface area of the basal lamina was also observed $(P=0.05$; Figure $4 C$ ). In contrast, the number of mast cells in the submucosa relative to the surface area of the basal lamina was lower in asthma compared with healthy controls $(P=0.006$; Figure $4 D)$; there was no difference in the number of mast cells below the basal lamina comparing subjects with and without EIB $(P=0.60$; Figure $4 \mathrm{E})$ or comparing the number of submucosal mast cells and severity of EIB $(P=0.20$; Figure $4 \mathrm{~F})$. In comparing the density of mast cells in each space relative to the volume of that space, we found the same relationships between epithelial mast cell infiltration and indirect AHR (Supplemental Figure 5, A-C), and observed a similar trend toward a reduction in the density of mast cells per submucosal volume in asthma, though these results did not reach statistical significance (Supplemental Figure 5, D and E).

To specifically characterize the shift in mast cells between the submucosa and epithelial compartments, we generated a ratio of mast cells in the epithelium relative to the submucosa using both quantitative metrics. We found that the ratio of the number of mast cells per area of the basal lamina in the epithelium relative to the number in the submucosa ( $\mathrm{MC} \# / \mathrm{BL}$ area ratio) was increased in asthma $(P=0.006$; Figure $4 \mathrm{G})$ and that this increase was specifically driven by the $\mathrm{EIB}^{+}$asthma group relative to the EIB $^{-}$asthma group $(P=0.009$; Figure $4 \mathrm{H})$ and the healthy controls $(P=0.0007)$. Further, there was a strong association between this ratio of mast cells and the severity of indirect AHR $\left(r^{2}=0.29, P=\right.$ 0.0007; Figure 4I). Similarly, the density of mast cells in the epithelium relative to the density of mast cells in the submucosa (MC volume density ratio) was increased in asthma $(P=0.02$; Supplemental Figure $5 \mathrm{G}$ ) in a manner that was driven by the $\mathrm{EIB}^{+}$asthma group $(P=0.002$; Supplemental Figure $5 \mathrm{H})$ and was associated with the severity of indirect AHR $\left(r^{2}=0.31, P=0.0005\right.$; Supplemental Figure 5I). These results are also illustrated in Supplemental Figure 6, which shows representative images of endobronchial biopsies from each of the groups showing the shift in the location of mast cells between the submucosa and epithelium in asthma. 
A

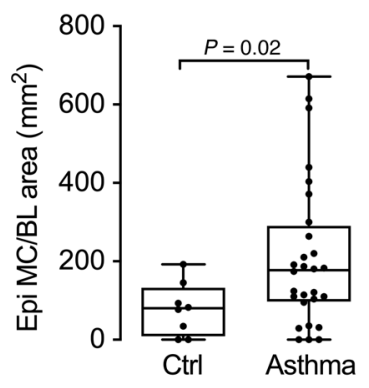

D

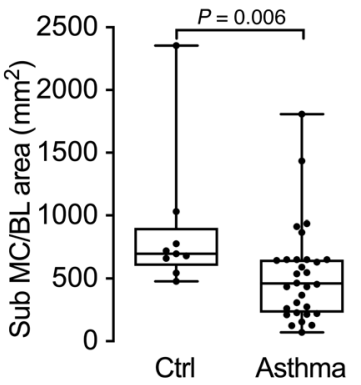

G

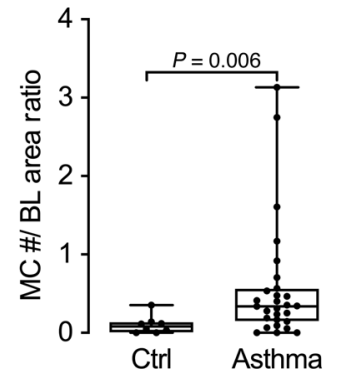

B

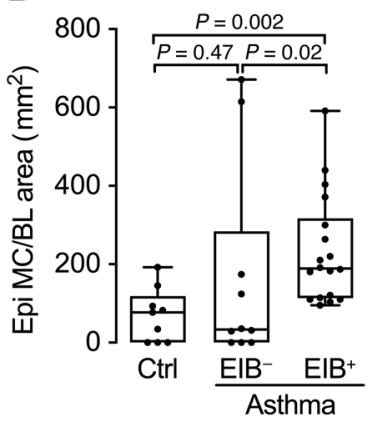

E

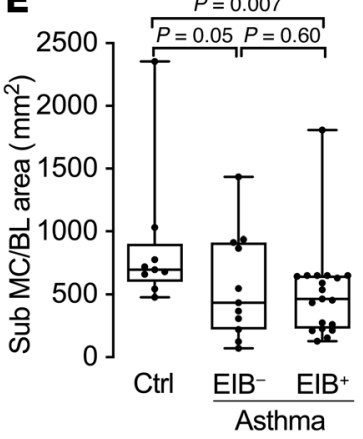

H

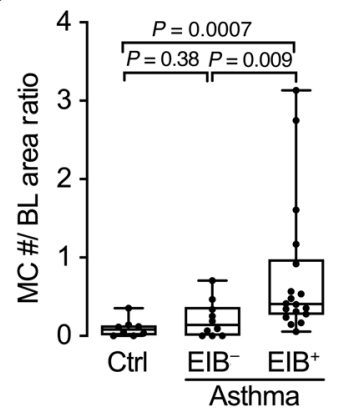

C

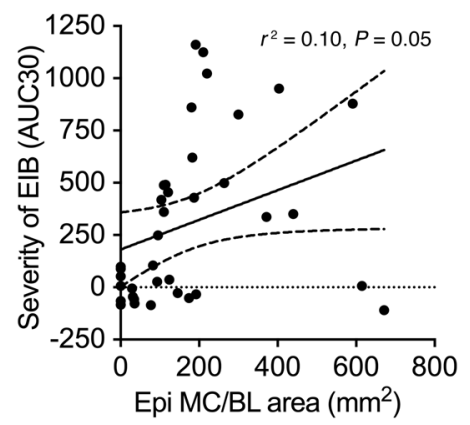

$\mathbf{F}$

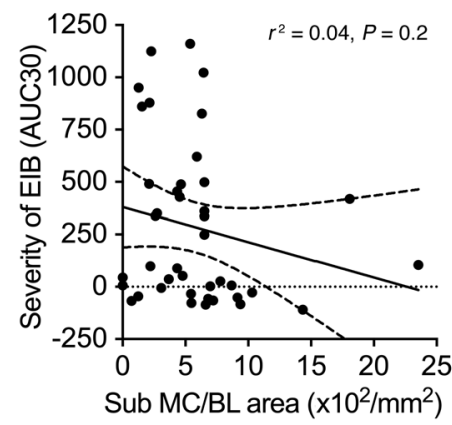

I

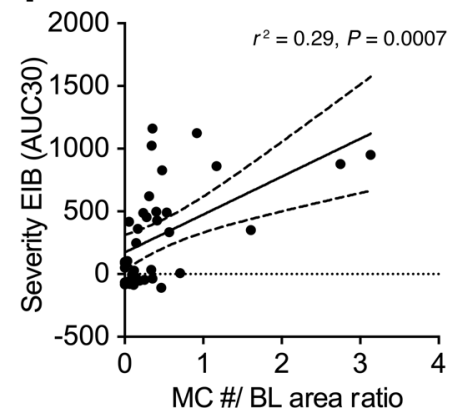

Figure 4. A shift in mast cells from the submucosa to the epithelium is associated with indirect AHR. (A) The number of intraepithelial mast cells relative to the area of the basal lamina (Epi MC/BL area) is increased in asthma compared with healthy controls. (B) It is highest in $\mathrm{EIB}^{+}$asthma subjects compared with EIB- subjects and healthy controls. (C) Additionally, it is significantly correlated with severity of indirect AHR measured by AUC30. (D-F) In contrast, the number of submucosal mast cells relative to the area of the basal lamina (Sub MC/BL area) is lower in asthma compared with healthy controls (D), is similar in $\mathrm{EIB}^{+}$and $\mathrm{EIB}^{-}$asthma (E), and is not correlated with indirect AHR (F). (C) The ratio of the number of mast cells per area of the basal lamina in the epithelium relative to the number in the submucosa is increased in asthma. (H) It is highest in the $\mathrm{ElB}^{+}$asthma subjects relative to the $\mathrm{EIB}^{-}$subjects and healthy controls. (I) Additionally, it is significantly associated with the severity of indirect AHR measured by AUC30. Group comparisons are shown as box plots with median, interquartile range, minimum, and maximum. Significance was assessed by the Mann-Whitney $U$ test (2-group) or the Kruskal-Wallis test with Dunn's post hoc test for multiple comparisons (3-group). Associations are by linear regression; shown are regression lines and 95\% confidence bounds.
Taken together, these results specifically demonstrate that in healthy individuals, mast cells are located predominantly in the submucosa, while these cells are shifted to the epithelial compartment in asthma. This finding further suggests the migration of mast cells from the submucosa to the epithelium in asthma and demonstrates that a shift in the location of mast cells from a predominantly submucosal location to the airway epithelium is the major alteration in asthma, and is closely associated with airway dysfunction in the form of indirect AHR.

The T2GM in induced sputum is a marker of mast cell infiltration of the airway epithelium. Type 2 inflammation is often viewed as a marker of eosinophilic inflammation. More recently, however, innate immune cells, including type 2 innate lymphoid cells (ILC2s), have emerged as a key source of IL-5 and IL-13 (33-35). Here we observed that type 2 inflammation reflected by the T2GM was closely associated with the quantity of mast cells in the airway epithelium relative to the basal lamina area $\left(r^{2}=0.35, P=0.002\right.$; Figure $5 \mathrm{~A}$ ), but not the quantity of mast cells in the submucosa relative to the basal lamina area $\left(r^{2}=0.04, P=0.34\right.$; Figure $\left.5 \mathrm{~B}\right)$. This finding specifically demonstrates that a shift in the location of mast cells is associated with type 2 inflammation, as the ratio of the quantity of mast cells above and below the basal lamina was strongly associated with the T2GM $\left(r^{2}=0.40, P=0.009\right)$, as was the volume density ratio of mast cells in the epithelium relative to the submucosa $\left(r^{2}=0.60, P<0.0001\right.$; Figure $\left.5 \mathrm{C}\right)$. This shift in the volume density ratio of mast cells was closely correlated with the expression of each type 2 gene, IL4 $\left(r^{2}=0.52, P<0.0001\right), I L 5\left(r^{2}\right.$ $=0.41, P=0.0008)$, and $I L 13\left(r^{2}=0.55, P<0.0001\right)$.

To assess the relationship between the T2GM and airway eosinophilia, we examined the relationship between the T2GM with the percentage of eosinophils in induced sputum and the concentration of induced sputum eosinophils. We found a modest association between the T2GM and the concentration of induced sputum eosinophils $\left(r^{2}=0.16, P=0.02\right.$; Figure $\left.5 \mathrm{D}\right)$, and no association with percentage of induced sputum eosinophils. The associations with each type 2 gene and the concentration of induced sputum eosinophils were modest: IL4 $\left(r^{2}=0.21, P=0.007\right)$, IL5 $\left(r^{2}=0.21, P=0.05\right)$, and $I L 13\left(r^{2}=0.09, P=0.09\right)$. These results demonstrate that type 2 inflammation is more closely related to a shift in the location of mast cells to the airway epithelium as compared with induced sputum eosinophilia in asthma.

The epithelial-derived cytokine IL-33 plays a unique role in the activation of type 2 gene expression in human mast cells. Because of the observed association of intraepithelial mast cells with 
A
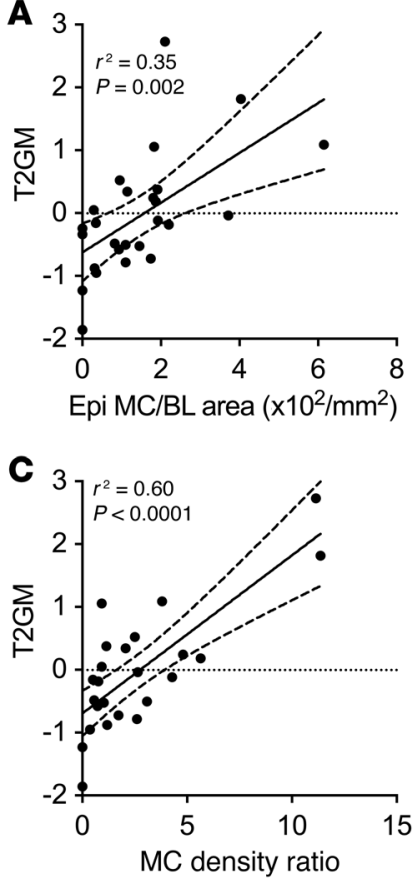

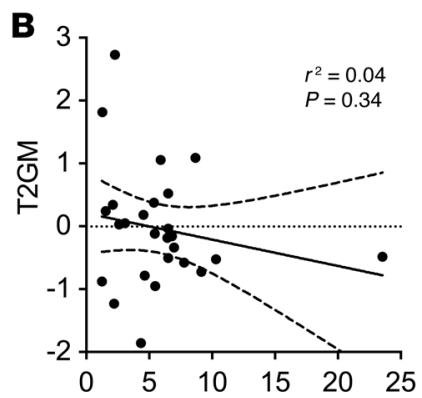

Sub MC/BL area $\left(\times 10^{2} / \mathrm{mm}^{2}\right)$

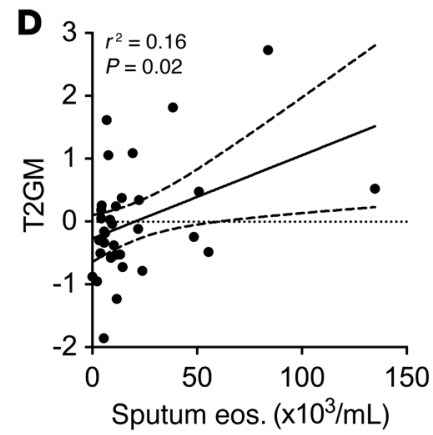

type 2 inflammation, we examined the regulation of mast cell type 2 gene expression by the epithelial-derived cytokines IL-33, IL-25, and TSLP. We investigated expression in primary human cord blood-derived mast cells (CBMCs), and also in the LAD2 human mast cell line (36) and the LUVA human mast cell line (37) to serve as technical replicates because of limitations in the ability to generate sufficient quantities of CBMCs for some of the complex ex vivo experiments. In CBMCs, we found that IL-33 induced the expression of IL5 and IL13 $(P<0.0001)$ but not IL4 $(P=0.81)$. In contrast, IL-25, TSLP, house dust mite (HDM) extract, and IL-13 did not individually induce the expression of type 2 cytokines (Figure 6A). In LAD2 cells, we similarly found that only IL-33 stimulation induced the expression of the type 2 cytokines IL5 $(P<0.0001)$ and IL13 $(P=0.0009)$ with minimal induction of $I L 4(P=0.65$; Supplemental Figure 7A). In LUVA cells IL-33 induced expression of IL13 but not IL4 or IL5 (Supplemental Figure 7B). Using the LAD2 cell line, we found that the addition of IL-25 or TSLP to IL-33 partially attenuated the IL-33induced expression of type 2 cytokines (Supplemental Figure 7A). Finally, we examined the release of IL- 5 and IL-13 protein and found that LUVA mast cells treated with IL-33 released large quantities of IL-13 and modest amounts of IL-5 after 24 and 48 hours in culture $(P<0.0001$; Figure 6B).

In an organotypic cell culture system, mast cells regulate the epithelial expression of IL-33 in a feed-forward loop. Because of the unique role of IL-33 in the induction of type 2 cytokines in mast cells, we examined the interaction between mast cells and the expression of key cytokines in the epithelium. We used an ex vivo model of differentiated primary epithelial cells in organotypic culture in which human mast cells were placed in the basolateral fluid for 48 hours either with or without treatment of the apical surface with HDM extract, modeling the function of intraepithelial mast cells. The mast cells were either primed with IL-33 for 4

Figure 5. Sputum type 2 gene expression is correlated with a shift in mast cells from the submucosa to the airway epithelium. (A and $B$ ) The sputum T2GM is correlated with the number of intraepithelial mast cells relative to the area of the basal lamina (Epi MC/BL area) (A), and not with the number of submucosal mast cells relative to the area of the basal lamina (Sub MC/BL area) (B). (C) The sputum T2GM is correlated with the volume density ratio of mast cells in the epithelium relative to the submucosa. (D) Sputum T2GM is also weakly correlated with sputum eosinophil concentration. All associations are by linear regression; shown are regression lines and $95 \%$ confidence bounds.

hours or not prior to coculture. We found that coculturing epithelial cells with LAD2 mast cells that were primed with IL-33 before coculture led to a marked amplification of epithelial IL33 expression $(P=0.02$; Figure 7A). It is notable that HDM treatment, which is known to cause an increase in IL-33 release as are other proteolytic allergens (38-40), caused a further amplification of epithelial IL33 expression over IL-33 priming alone $(P=0.007)$, suggesting that persistent IL-33 activation of mast cells occurs in this coculture model. We found the same results using LUVA mast cells in coculture, both the significant increase in epithelial IL33 expression in coculture with IL-33-primed LUVA mast cells $(P=0.0004)$ and the amplification by treatment of epithelial cells with HDM extract $(P=0.02$; Figure $7 B)$. Finally, we confirmed these results using primary human CBMCs, including the effects of priming and the further amplification of epithelial IL33 following HDM stimulation of the apical surface $(P=0.01$; Figure 7C). These results demonstrate that IL-33-primed mast cells regulate the epithelial expression of IL33 and suggest that further release of IL-33 in response to HDM extract amplifies this feed-forward loop. Providing further evidence of this feed-forward loop, we found that the levels of IL-33 protein were significantly elevated in the basolateral media only when IL-33-primed mast cells were added to the coculture system in our model of coculture with HDM-treated epithelial cells differentiated in organotypic culture $(P<0.0001$; Figure 7D). Although we can-
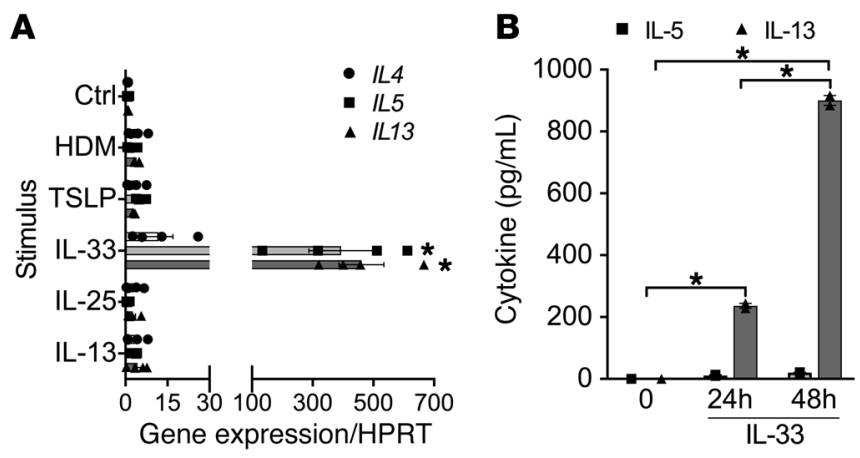

Figure 6. IL-33 uniquely induces production of type 2 cytokines in mast cells. (A) IL-33 induced gene expression of the type 2 cytokines IL5 and IL13, and to a lesser extent IL4, in primary human CBMCs compared with unstimulated control (Ctrl), whereas IL-25, TSLP, HDM extract, or IL-13 did not ( $n=4$ per condition). ${ }^{*} P<0.0001$ vs. Ctrl. (B) IL-33 induced production of IL-13 protein and to a lesser extent IL-5 protein in LUVA mast cells ( $n=$ 2 per condition at 3 time points). Differences between multiple conditions were assessed by 1-way ANOVA with correction for multiple comparisons. Shown are mean values and SEM bars. ${ }^{*} P<0.0001$. 
A
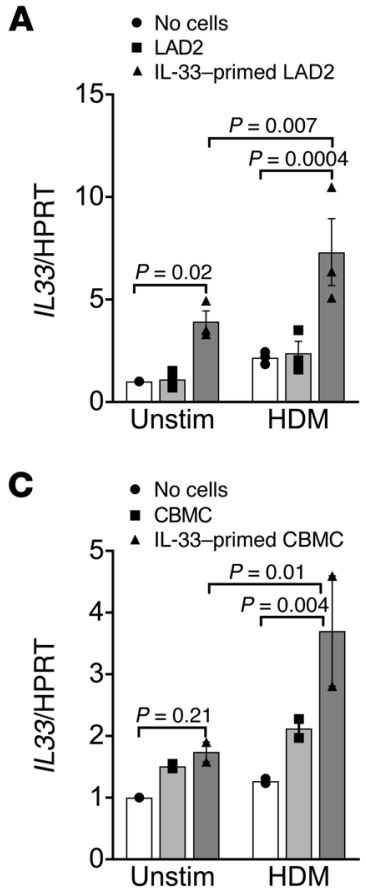

B

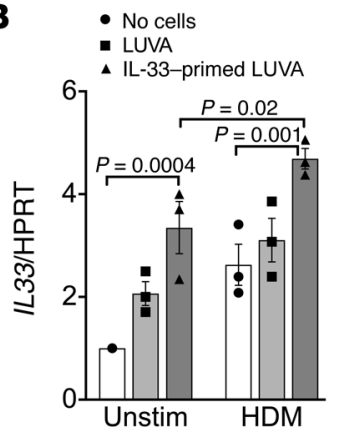

D

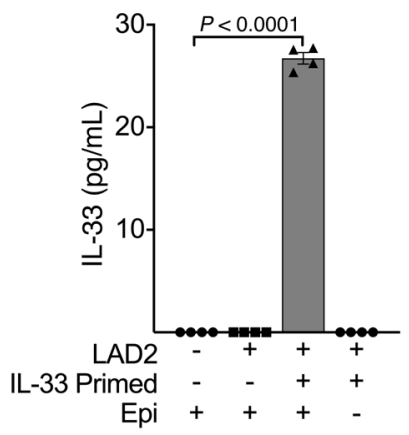

Figure 7. Mast cells regulate the epithelial expression of IL33 in a feed-forward loop. In a coculture system with differentiated epithelial cells cocultured with or without mast cells for 48 hours, priming of the mast cells with IL-33 significantly amplified the epithelial expression of IL33. Stimulation of the epithelial surface with HDM further amplified IL33 expression. Similar results were identified for LAD2 mast cells $(n=3$ per condition) (A), LUVA mast cells ( $n=3$ per condition) (B), and primary CBMCs ( $n=2$ per condition) (C). (D) IL-33 protein was detected in the basolateral media only when IL-33-primed mast cells were added to the coculture system in which HDM was added to the apical surface $(n=4$ per condition). IL-33 protein was not detectable when IL-33-primed mast cells that were similarly exposed to HDM were cultured in the absence of the epithelium. Differences between multiple conditions were assessed by 1-way ANOVA with correction for multiple comparisons. Shown are mean values and SEM bars.

Since recent work found that IL-33-stimulated mast cells induce IL-13-mediated genes in the epithelium (42), we examined the dependence on IL-33 and IL-13 after priming LAD2 mast cells with IL-33 using blocking antibodies in our coculture system. We found that the amplification of epithelial IL33 by IL-33-primed mast cells could be inhibited by blockade of IL-33 during coculture $(P=0.003$; Figure $8 \mathrm{~A})$. The further amplification of epithelial IL33 with both IL-33-primed mast cells and HDM stimulation of the epithelial cells was significantly attenuated via IL-33 blockade $(P<0.0001$; Figure 8A). Our prior results demonstrate that HDM leads to a persistent increase in IL33 expression, and these studies further confirm the dependence on persistent IL-33 activation in this feed-forward loop that regulates epithelial IL33 expression through mast cells. As we have shown that IL-33 strongly induces IL13 expression and release in mast cells, these results suggest that the effects on the epithelium may be mediated by IL-13, so we

not directly ascertain the source of IL-33 protein in this experiment definitively, we found that the levels of IL-33 protein were not measurable when IL-33-primed mast cells were washed, transferred to a new well, and similarly treated with HDM in the absence of the epithelium, so we believe the production is from the epithelium. Further, although mast cell production of IL-33 has been described (41), we have found that IL-33 priming of mast cells does not lead to an increase in the expression of IL33 by mast cells (data not shown).

Feed-forward amplification of epithelial IL-33 gene expression by mast cells is mediated by $I L-33$, and is not a consequence of IL-13 signaling. To examine whether IL-33 activation of mast cells is critical for the amplification of epithelial IL33 expression rather than a more general feature of mast cell activation, we compared priming of mast cells with IL-33 to priming with more general stimuli of mast cell activation, including IgE-mediated degranulation following passive sensitization as well as phorbol 12-myristate 13-acetate-mediated (PMA-mediated) activation. Furthermore, to exclude the possibility that the cells were being activated in an autocrine manner, we also primed with unstimulated mast cell supernatant as a control condition. We found that while IL-33-primed LAD2 mast cells amplified epithelial IL-33 production either with or without HDM treatment of the epithelial surface, activating mast cells by IgE-mediated degranulation or PMA stimulation did not alter epithelial IL33 expression (Supplemental Figure 8A). We observed the same results with LUVA mast cells (Supplemental Figure $8 \mathrm{~B})$. We also found no evidence that autocrine activation by a mast cell-derived product was involved in the regulation of epithelial IL-33.

A
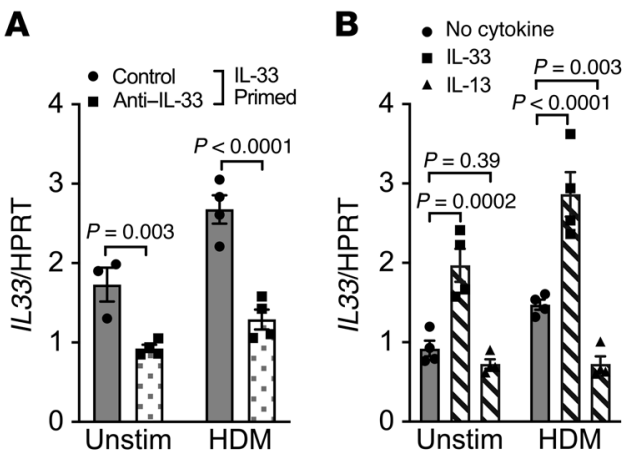

C

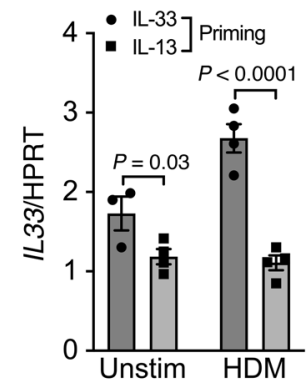

Figure 8. Feed-forward amplification of epithelial IL33 gene expression is mediated by IL-33 and is not a consequence of IL-13 signaling. (A) A blocking antibody against IL-33 during the 48 hours of coculture reduced the amplification of epithelial IL33 expression during coculture with IL-33-primed LAD2 mast cells, particularly when the apical surface of the epithelium was treated with HDM. (B) Direct treatment of differentiated primary epithelial cells alone (without mast cells) with IL-33 significantly increased the expression of $I L 33$, while treatment with IL-13 did not induce the expression of epithelial IL33. HDM also induced expression of epithelial IL33 $(P=0.02)$, which was further augmented by treatment with IL-33 in the basolateral compartment and was diminished by the addition of IL-13 in the basolateral fluid. (C) Priming mast cells with IL-33 before coculture increased epithelial IL33 expression in comparison with priming with IL-13 ( $n=4$ per condition for all conditions, except one condition in which poor quantitative PCR amplification of the housekeeping gene occurred). Differences between multiple conditions were assessed by 1-way ANOVA with correction for multiple comparisons. Shown are mean values and SEM bars. 


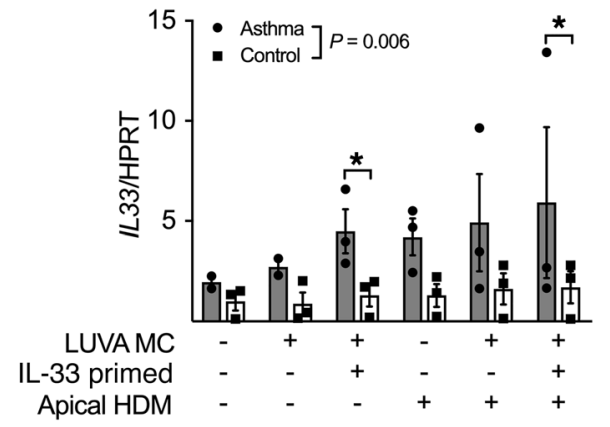

Figure 9. Feed-forward amplification of epithelial IL33 expression is higher in epithelial cells from children with asthma compared with healthy children. Amplification of epithelial IL33 expression by coculture with IL-33-primed LUVA mast cells was greater in epithelial cells isolated from children with asthma compared with epithelial cells isolated from healthy nonatopic children ( $n=3$ per group). Significance was assessed by 2-way ANOVA. There was a notable trend toward an increased effect of IL-33-primed mast cells on epithelial cells derived from children with asthma. ${ }^{*} P=0.1$ for the post hoc test.

treated epithelial cells in organotypic culture directly with either IL-33 or IL-13, and found that while IL-33 induced the expression of IL33 in the epithelium $(P=0.0002)$ as has been noted in other cells (43), IL-13 itself did not induce the expression of IL33 (Figure 8B). When epithelial cells were treated with HDM, there was an increase in IL33 expression as seen in earlier experiments $(P=0.02)$. In this context, the addition of IL-33 to HDM-treated epithelial cells resulted in a further increase in epithelial IL33 expression $(P<0.0001)$, while treatment with IL-13 significantly decreased the expression of $I L 33$ ( $P=0.003$; Figure $8 \mathrm{~B})$, indicating that IL-13 serves as a negative regulator of this system. As this result might suggest that IL-13 acts indirectly on the epithelium through mast cells, we primed mast cells with either IL-13 or IL-33 and found that while IL-33-primed mast cells increased epithelial IL33, IL-13-primed mast cells did not ( $P=0.03$ without and $P<0.0001$ with HDM treatment of the epithelium; Figure $8 \mathrm{C}$ ). These results demonstrate that the feed-forward loop leading to enhanced epithelial IL33 expression is dependent on mast cells and the persistent effects of IL-33 in coculture, which leads to enhanced expression of type 2 cytokines; however, IL-13 itself is not the mediator of this effect, and actually decreases the HDM-mediated increase in epithelial IL33 expression, suggesting a counterregulatory system.

Feed-forward amplification of epithelial IL33 expression is accentuated in primary epithelial cells derived from subjects with childhood-onset asthma. Although most studies have not identified a major increase in epithelial IL33 gene expression in asthma during stable disease, and similarly we did not see an increase in IL33 expression in epithelial brushing in our cohort (data not shown) (9), there is evidence of increased IL-33 protein production and altered expression of a recently described splice variant suggesting complex regulation $(9,44,45)$. Further, previous work has demonstrated that IL-33 production is largely from basal cells rather than the ciliated cells that predominate in epithelial brushings (45). To further translate our findings to asthma, we compared the effects of LUVA mast cell coculture and IL-33 priming on primary airway epithelial cells isolated from children with asthma compared with epithelial cells isolated from healthy nonatopic children. We found the same pattern of amplification of epithelial IL33 expression by coculture with IL-33-primed LUVA mast cells, but there was a greater effect in the epithelial cells isolated from children with asthma compared with epithelial cells isolated from healthy nonatopic children $(P=0.006$, overall difference in phenotype, control vs. asthma; Figure 9 and Supplemental Table 3). The accentuated effects of priming the mast cells with IL-33 either with or without HDM stimulation showed a notable trend toward increased effect of mast cells on epithelial cells derived from children with asthma $(P=0.1$, control vs. asthma). These results indicate that the epithelial-mast cell feed-forward loop regulating the epithelial expression of IL33 is amplified in subjects with asthma compared with healthy controls, both an overall difference in the epithelial response to coculture with mast cells, and specifically a heightened response to IL-33 acting through mast cells.

\section{Discussion}

The present study reveals a clear relationship between type 2 gene expression, the location of mast cells within the airway wall, and features of indirect AHR in asthma. These findings are of key importance as AHR is central to the pathophysiology of asthma, and indirect AHR is a specific phenotypic manifestation of asthma $(1,2)$. Although indirect AHR has been related to general features of inflammation (46), our study specifically defines the underlying alterations in the airway wall that are associated with this phenotype. Specifically, we demonstrate that increased type 2 gene expression in the airways is associated with both indirect AHR and increased mast cell gene expression in the airways, as well as a shift in the location of mast cells from the submucosal to the epithelial compartment. These results suggest that type 2 inflammation is directly related to mast cell infiltration of the epithelium and to a specific mast cell subtype with strong expression of tryptase and carboxypeptidase A3.

In further ex vivo experimentation, we demonstrate that IL-33 has a unique role in the induction of type 2 cytokines in mast cells, and that mast cells primed with IL-33 regulate the epithelial expression of IL-33 in a feed-forward loop, indicating the presence of a mast cell-derived product that enhances epithelial IL33 expression. This mast cell-dependent feed-forward loop is augmented by exposure to HDM allergen, which provides a source of IL-33 to perpetuate the feed-forward loop through mast cells. Critically, we found that this feed-forward loop is accentuated in primary airway epithelial cells from children with asthma relative to healthy controls, which indicates that this feed-forward amplification between IL-33 and type 2 inflammation through mast cells is enhanced by a disease-related factor present in epithelial cells from children with asthma. These results reveal a fundamental basis for type 2 inflammation in the human airway and suggest that a break in this feed-forward loop might attenuate airway type 2 inflammation.

Type 2 inflammation can be characterized directly by the expression of the classical type 2 cytokines IL-4, IL-5, and IL-13 as we did in the present study. It can also be characterized indirectly based on the effects of this inflammation on the airway epithelium. In particular, IL-13 has been demonstrated to have important epithelial effects by inducing the epithelial-derived genes 
CLCA1, SERPINB2, and POSTN $(6,23)$. The source of IL-13 leading to effects on the airway epithelium has often been attributed to effector T cells, which are well established as sources of IL-13 and other type 2 cytokines $(47,48)$. However, several subsequent studies have revealed that other cells may be more important sources of IL-13, and recently there has been particular focus on ILC2s $(33-35,49)$. The relationship we observed in this study between type 2 cytokines, in particular IL-13, mast cell genes, and a shift in mast cells from the submucosa to the epithelium suggests that in humans, mast cells can be a major source of type 2 cytokines in the airways of individuals with asthma, as has been suggested by some previous studies $(7,50)$; this relationship is particularly notable for those individuals with indirect AHR, the most specific feature of asthma. Furthermore, our ex vivo experiments demonstrate directly that mast cells and airway epithelial cells are sufficient to sustain type 2 inflammation. Prior studies in both mice and humans have revealed that mast cells generate IL-13 in response to IL-33 (51-53), consistent with our findings here. We further demonstrate that among the epithelial-derived cytokines that ligate mast cell receptors, IL-33 is unique in its ability to markedly induce type 2 cytokine expression and the sustained production of these proteins, particularly IL-13. Because such IL-33-primed mast cells feed forward to increase the expression of IL-33 in the epithelium, our results indicate that this interaction between epithelial cells and mast cells can generate the expression of type 2 cytokines in asthma.

A key strength of the present study is that, to our knowledge, it is the first to use 3-dimensional quantitative morphometry in human airway biopsies to quantify the density of mast cells in both the epithelium and submucosa, which provides key insights that cannot be adequately assessed by 2 -dimensional methods. The density of intraepithelial mast cells was tightly correlated with a direct measure of the expression of type 2 cytokines in the present study, consistent with previous indirect observations (54). We demonstrate here that these intraepithelial mast cells represent a shift in the location of mast cells from the submucosa to the epithelium, and this shift in location of mast cells is closely correlated with indirect AHR. This finding is consistent with the clinical observations that mast cell products are released following indirect airway challenge (55) and mast cell-stabilizing drugs are effective in EIB (56). Another unique observation was that the shift in the location of mast cells suggests that mast cells may transit from the submucosa to the intraepithelial space in asthma. A recent study using 2-dimensional quantification noted that the number of mast cells per area of the submucosa was decreased in severe asthma relative to healthy controls (57), and a prior study showed that among subjects with asthma the number of mast cells per area was decreased in association with asthma severity (58). Based on our study design, we can be confident that the altered mast cell distribution we observed is not confounded by corticosteroids or the quantification method. We can conclude that mast cell location is closely associated with both phenotype and endotype, with intraepithelial mast cells playing a key role in type 2 inflammation and indirect AHR in asthma.

Our study further supports a change in the mast cell type from the typical mucosal mast cell that expresses tryptase alone $\left(\mathrm{MC}_{\mathrm{T}}\right)$ to a distinct mast cell subtype in asthma that expresses both trypt- ase and carboxypeptidase $\mathrm{A} 3\left(\mathrm{MC}_{\mathrm{T} / \mathrm{CPA} 3}\right)$. These $\mathrm{MC}_{\mathrm{T} / \mathrm{CPA} 3}$ cells are also distinct from the typical submucosal mast cells $\left(\mathrm{MC}_{\mathrm{TC}}\right)$ that also express chymase in addition to other granule proteases (59). Although our laboratory $(8)$ and others $(54,60)$ have previously described this alteration in mast cell gene expression, our results here further demonstrate that these proteases are tightly linked to the expression of type 2 cytokines in the airways, and although we do not have samples to assess the expression of mast cell genes in the submucosa, these results suggest that mast cells migrating to the epithelium may lose expression of chymase. These findings could be of importance because tryptase cleavage of IL-33 proteolytically activates the cytokine for binding to the ST2 receptor while chymase cleaves IL-33 in a manner that leads to the inactivation of IL-33 (61-64). The distinct mast cell populations could serve both to amplify type 2 inflammation at the mucosal surface and to inactivate IL-33 in the submucosa to prevent the unwarranted activation of innate cells. Such a mechanism could be protective in the context of helminth infection, but detrimental in the context of allergy and asthma (65).

Although the mast cell-mediated increase in epithelial IL-33 was clearly dependent on IL-33 during the priming stage and during coculture, and IL-33 markedly induced type 2 cytokines in mast cells, our results demonstrate clearly that IL-13, acting either on the epithelium or in an autocrine manner on mast cells, is not the factor leading to the increase in epithelial IL-33. In contrast, we found that IL-13 decreases IL33 expression in the epithelium, suggesting that this is an endogenous mechanism to restrain IL33 expression. We found that IL-33 itself is partially responsible for the increase in IL33 expression in the epithelium; however, we have not yet identified the mast cell factors responsible for the increase in epithelial IL-33. This remains an important open question that could lead to important insight into novel therapeutic approaches to type 2 inflammation. It could be that another IL-1 family protein such as IL-1 $\beta(66,67)$ may explain our finding. Considering this mechanism, the increase in epithelial IL-33 mediated through this feed-forward loop observed in the primary epithelial cells from children with asthma could be due in part to an increased expression of ST2 in their primary epithelial cells, as has been described in tissue sections from severe asthma (68). This accentuation of the feed-forward loop in epithelial cells derived from individuals with asthma could also be the consequence of an increase in basal epithelial cells, which serve as the major source of IL-33 $(45,69,70)$. Alternatively, a separate signaling pathway may be responsible for this effect. Further investigation of the molecular differences of the epithelial cells in relevant asthma populations is needed to fully understand this feed-forward loop.

In summary, our results reveal a clear relationship linking the expression of type 2 cytokines in the airway, a shift in the location of mast cells from the submucosa to the epithelium, and indirect AHR. Furthermore, intraepithelial mast cells with a specific granule expression profile that are structurally within the epithelium rather than the submucosa drive this association. Using ex vivo modeling, our results identify a novel feed-forward loop dependent on IL-33 and mast cells that leads to the amplification of epithelial IL33 expression and type 2 cytokines in mast cells. As indirect AHR is a central and specific manifestation of asthma, these findings pro- 
vide important phenotype-endotype definition to the basis of type 2 inflammation in human asthma that can inform investigations of targeted therapeutic strategies to modulate type 2 inflammation.

\section{Methods}

Additional detailed experimental methods are provided in Supplemental Methods online.

Adult study subjects. We used endobronchial biopsies, epithelial brushings, and induced sputum from a repository collected at the University of Washington designed to examine differences between mild to moderate asthmatics with and without EIB and nonasthmatic controls (9). Subjects with asthma had a physician diagnosis of asthma for at least 1 year, and used only an inhaled $\beta_{2}$-agonist for asthma treatment during the study. A methacholine challenge with a $\mathrm{PC}_{20}$ (concentration of methacholine needed to produce a $20 \%$ fall in $\mathrm{FEV}_{1}$ ) of less than $4 \mathrm{mg} / \mathrm{mL}$ was used to confirm the diagnosis of asthma. A dry air exercise challenge was conducted at least 2 days after the methacholine challenge. Based on the results of the exercise challenge, participants with asthma were characterized as EIB ${ }^{+}$if they had a fall in $\mathrm{FEV}_{1}$ of at least $10 \%$ following exercise challenge and $\mathrm{EIB}^{-}$if they had a $\leq 7 \%$ fall in $\mathrm{FEV}_{1}$ following exercise challenge $(56,71)$. Control subjects without asthma were enrolled who had an $\mathrm{FEV}_{1}$ of at least $80 \%$ predicted, a negative methacholine challenge $\left(\mathrm{PC}_{20} \geq 8 \mathrm{mg} / \mathrm{mL}\right)$, a negative dry air exercise challenge test $\left(<7 \%\right.$ fall in $\mathrm{FEV}_{1}$ following exercise), and no more than 1 positive skin prick test from a panel of 14 aeroallergens. None of the subjects had a history of smoking cigarettes within the prior year or had 7 or more pack-years total of smoking.

Either epithelial brushings or endobronchial biopsy samples were available from 10 controls, $12 \mathrm{EIB}^{-}$asthmatics, and $19 \mathrm{EIB}^{+}$asthmatics. Endobronchial biopsy tissue was inadequate for stereology assessment in 1 control, $2 \mathrm{EIB}^{-}$asthmatics, and $1 \mathrm{EIB}^{+}$asthmatic. Insufficient RNA was available from the epithelial brushings for the PCR analysis in 1 control, $2 \mathrm{EIB}^{-}$asthmatics, and $2 \mathrm{EIB}^{+}$asthmatics.

Induced sputum and research bronchoscopy. Induction of sputum was conducted with $3 \%$ saline via an ultrasonic nebulizer for 20 minutes (55). Research bronchoscopy was conducted 2-10 days after induction of sputum in accordance with established guidelines (72). During bronchoscopy, 4 epithelial brushings were obtained from second- to fifth-generation airways of the left lower lobe and lingua using a 3-mm nylon cytology brush. Four to six endobronchial biopsies were obtained from second- to fifth-generation carina of the right lower and middle lobes using a 1.8-mm forceps. The biopsies were fixed in methyl Carnoy's solution before embedding in paraffin.

Quantitative PCR and T2 gene mean. Real-time PCR analysis of induced sputum cells was conducted using TaqMan-based quantitative PCR methods (23). RNA from induced sputum cells from 37 asthmatic participants and 15 healthy control subjects was analyzed for expression of 8 genes relevant to airway inflammation: IL4, IL5, IL13, IFNG, CMA1, TPSAB1, CPA3, and ARG2. The expression of 4 housekeeping genes, GAPDH, PPIA, YWHAZ, and PSMB2, was also measured.

Real-time PCR analysis of mast cell genes in epithelial brushings was conducted using TaqMan primer probe sets from Applied Biosystems with quantification relative to a standard curve of the gene copy number (73). Quantities of the specific transcripts of TPSAB1, CPA3, and CMA1 were determined by comparison of $\mathrm{Ct}$ values observed in each sample with $\mathrm{Ct}$ values obtained from standard curve generated using a dilution series of plasmid DNA containing a single copy of the gene of interest.
Cytokine measurement by ELISA. Human IL-5, IL-13, and IL-33 protein content from cell culture supernatants was determined by ELISA.

Immunohistochemistry and design-based stereology. We previously used the physical dissector method to enumerate the density of mast cells in the epithelial layer (9). Here we applied stereology methods to simultaneously quantify the density of mast cells in the epithelium and submucosa. Mast cells in endobronchial tissue were localized using a murine monoclonal anti-tryptase antibody (clone AA1, Neomarkers), and hematoxylin was used as a nuclear counterstain. To use the physical dissector, adjacent sections were aligned and sampled, counting frames were superimposed on the images, and regions of interest were identified. Mast cell nuclei coming into view in the dissector between the "reference" and "look-up" sections were counted. A point associated with each counting frame was used to determine the reference volume by enumerating points hitting the submucosa and the epithelium. This method determined the volume density of mast cells in the epithelium and in the submucosa. We also determined the surface area of the basal lamina relative to the submucosal and epithelial volumes using a separate line and point probe system. By dividing the basal lamina area relative to the volume of each space by the mast cell volume density in each space, we determined the number of mast cells in each space relative to the surface area of the basal lamina.

Human mast cell culture. Human umbilical cord blood was obtained from anonymous donors to Bloodworks Northwest in accordance with established institutional guidelines. After dextran sedimentation, $\mathrm{CD}_{4} 4^{+}$cells were isolated from the mononuclear cell layer by immunomagnetic selection and placed in RPMI 1640 medium containing $10 \% \mathrm{FCS}$ and $2 \mathrm{mM} \mathrm{L}$-glutamine. During the first week of culture, the CD34-selected cord blood cells were treated with IL-3, IL-6, and stem cell factor (SCF), and during subsequent weeks, nonadherent cells were transferred to a new flask containing IL-6 and SCF (74). LUVA and LAD2 human mast cell lines were maintained in STEM Pro34 SFM Complete Medium (Invitrogen) with L-glutamine and human SCF. LAD2 cells were propagated by weekly hemidepletion.

Primary bronchial epithelial cell culture. Primary bronchial epithelial cells (BECs) were isolated from tracheal segments that were collected from a discarded segment of donor airway at the time of lung transplant (75). The procedure for isolation of epithelial cells was approved by the University of Washington Human Subjects Review Committee. Cells were cryopreserved and/or subcultured at 90\%-95\% confluence. Cryopreserved primary epithelial cells at passage 1 or 2 were used for differentiated air-liquid interface (ALI) organotypic cultures (75).

Epithelial-mast cell coculture model system. In initial experiments with mast cells alone, CBMCs, LUVA cells, or LAD2 cells were treated with IL-33, IL-25, TSLP (alone or in combination), HDM, and IL-13, and RNA was isolated after 4 hours of culture, or the supernatant was collected for protein analysis after 48 hours. We extended these results to a model of primary human BECs cocultured with LAD2 cells, LUVA cells, or CBMCs that were primed with different stimuli such as IL-33 for 4 hours or unprimed in a separate dish, washed, and then resuspended in ALI media and transferred to the basolateral compartment of the Transwell-containing culture dish for coculture with primary BECs in organotypic culture. HDM or PBS was then added to the epithelial cells in the apical compartment of the Transwell and allowed to incubate at $37^{\circ} \mathrm{C}$ for 4 hours. The PBS or HDM was then removed from the apical compartment, and the epithelial cells were 
washed with PBS and allowed to incubate for a total of 48 hours. RNA was isolated from the epithelial cells after 48 hours, and in some cases the basolateral fluid was collected for cytokine analysis. In our primary model, we compared IL-33 priming to no stimulus before transfer into coculture. In additional experiments, we compared priming with IL-33 for 4 hours versus treatment of mast cells on the plate prior to transfer with HDM, PMA, LAD2 supernatant, and LUVA supernatant, and passive sensitization with IgE followed by IgE cross-linking with the CRA1 antibody (IgE/CRA1) (9).

Pediatric study subjects and primary bronchial epithelial cell culture. Children ages 6-18 years who were undergoing an elective surgical procedure requiring endotracheal intubation and general anesthesia were recruited for this study. Inclusion and exclusion criteria for children with atopic asthma included a 1-year history of physician-diagnosed asthma; use of a short-acting $\beta$-agonist at least twice a month or daily use of an inhaled corticosteroid or leukotriene receptor antagonist; birth at 36 weeks or more of gestation; and 1 or more of the following atopic features: history of positive skin prick test or positive serum-specific IgE for a common aeroallergen, elevated serum total IgE, history of physician-diagnosed allergic rhinitis, and history of physician-diagnosed atopic dermatitis. Inclusion and exclusion criteria for healthy children included birth at 36 weeks or more of gestation, lack of atopy and asthma by the above definitions, lack of any other clinical diagnosis of lung disease, and lack of a family history of asthma.

During the elective surgery, 3 epithelial brushings were obtained, and BECs were established in primary culture and cryopreserved as previously described $(76,77)$. A blood sample at the time of surgery was used to measure total serum IgE and allergen-specific IgE to dust mites (Dermatophagoides farinae and Dermatophagoides pteronyssinus), cat epithelium, dog epithelium, Alternaria alternata, Aspergillus fumigatus, and timothy grass. A clinical follow-up visit was completed within 2 months of elective surgery and collection of BECs from subjects, at which time spirometry was conducted before and after the administration of a bronchodilator, and the fraction of exhaled nitric oxide (FeNO) was assessed (78).

Phenotyped primary epithelial cell-mast cell coculture model. Pediatric BECs differentiated in organotypic cultures were cocultured with unprimed LUVA mast cells or with LUVA cells that were first primed with IL-33 for 4 hours as described previously except that the epithelial cells were differentiated in PneumaCult-ALI Medium (Stemcell Technologies). Following coculture of BECs and LUVA cells for 48 hours, RNA was extracted from BECs, and IL33 expression was determined as described above.
Statistics. For comparisons among groups, $P$ values were calculated as appropriate for the data - Fisher's exact test for categorical data, a 2-tailed Student's $t$ test for 2-group comparisons for normally distributed continuous data, and a Mann-Whitney $U$ test for 2-group comparisons for non-normally distributed continuous data. A 1-way ANOVA with correction for multiple comparisons using the 2-stage step-up method of Benjamini, Krieger, and Yekutieli was used for multiple-group comparisons of normally distributed continuous data, and a Kruskal-Wallis test with Dunn's post hoc test for multiple-group comparisons of non-normally distributed continuous data. A 2-way ANOVA was used to assess differences between the responses of epithelial cells from the different groups to coculture with mast cells. Associations between continuous variables were assessed by linear regression. A $P$ value less than 0.05 was considered significant.

Study approval. In adults, written informed consent was obtained from all participants prior to inclusion in the study, and the University of Washington Institutional Review Board approved the study protocol. In children, parental informed consent and assent from the child were obtained prior to inclusion in the study, and the Seattle Children's Hospital Institutional Review Board approved the study protocol.

\section{Author contributions}

MCP and TSH conceived and designed studies. YL, SL, JSD, JDN, CCC, ML, JSD, MCP, and TSH performed experiments. MCA, JSD, AMP, WAA, CWF, MCP, and TSH analyzed and interpreted the results of the experiments. MCA and TSH wrote the manuscript. MCA, YL, SL, JSD, JDN, CCC, AMP, WAA, ML, CWF, MSM, SFZ, $\mathrm{MCP}$, and TSH edited and revised the manuscript, and all authors approved the final version of the manuscript.

\section{Acknowledgments}

The authors thank the staff of the University of Washington Histology and Imaging Core, especially Brian Johnson, for assistance with histologic analyses. The authors thank Taha Al-Shaikhly for assistance with the graphical abstract. This work was supported by NIH grants R01HL089215 and K24AI130263 to TSH, R01HL12836 to JSD, EPA STAR R835738 to WAA, U19AI125378 to SFZ, and F32HL134217 to JDN.

Address correspondence to: Teal S. Hallstrand, Center for Lung Biology, Box 358052, University of Washington, 850 Republican Street, Seattle, Washington 98109-4714, USA. Phone: 206.221.0523; Email: tealh@uw.edu.
1. Coates AL, et al. ERS technical standard on bronchial challenge testing: general considerations and performance of methacholine challenge tests. Eur Respir J. 2017;49(5):1601526.

2. Hallstrand TS, et al. ERS technical standard on bronchial challenge testing: pathophysiology and methodology of indirect airway challenge testing. Eur Respir J. 2018;52(5):1801033.

3. Martinez FD. Links between pediatric and adult asthma. J Allergy Clin Immunol. 2001;107(5 suppl):S449-S455.

4. Woodruff PG et al. T-helper type 2-driven inflammation defines major subphenotypes of asthma. Am J Respir Crit Care Med. 2009;180(5):388-395.
5. Cabral AL, Conceição GM, Fonseca-Guedes CH, Martins MA. Exercise-induced bronchospasm in children: effects of asthma severity. Am J Respir Crit Care Med.1999;159(6):1819-1823.

6. Woodruff PG, et al. Genome-wide profiling identifies epithelial cell genes associated with asthma and with treatment response to corticosteroids. Proc Natl Acad Sci U S A. 2007;104(40):15858-15863.

7. Bradding $P$, et al. Interleukin- $4,-5$, and -6 and tumor necrosis factor-alpha in normal and asthmatic airways: evidence for the human mast cell as a source of these cytokines. Am J Respir Cell Mol Biol. 1994;10(5):471-480.

8. Hallstrand TS, et al. Transglutaminase 2, a novel regulator of eicosanoid production in asthma revealed by genome-wide expression profiling of distinct asthma phenotypes. PLoS One. 2010;5(1):e8583.

9. Lai Y, et al. Increased density of intraepithelial mast cells in patients with exercise-induced bronchoconstriction regulated through epithelially derived thymic stromal lymphopoietin and IL-33. J Allergy Clin Immunol. 2014;133(5):1448-1455.

10. Hallstrand TS, Hackett TL, Altemeier WA, Matute-Bello G, Hansbro PM, Knight DA. Airway epithelial regulation of pulmonary immune homeostasis and inflammation. Clin Immunol. 2014;151(1):1-15.

11. Beale J, et al. Rhinovirus-induced IL-25 in asthma exacerbation drives type 2 immunity and 
allergic pulmonary inflammation. Sci Transl Med. 2014;6(256):256ra134.

12. Ying $S$, et al. Thymic stromal lymphopoietin expression is increased in asthmatic airways and correlates with expression of Th2-attracting chemokines and disease severity. JImmunol. 2005;174(12):8183-8190.

13. Iijima $\mathrm{K}$, et al. IL-33 and thymic stromal lymphopoietin mediate immune pathology in response to chronic airborne allergen exposure. J Immunol. 2014;193(4):1549-1559.

14. Nagarkar DR, et al. Airway epithelial cells activate $\mathrm{TH} 2$ cytokine production in mast cells through IL-1 and thymic stromal lymphopoietin. J Allergy Clin Immunol. 2012;130(1):225-232.e4.

15. Zasłona $Z$, et al. Resident alveolar macrophages suppress, whereas recruited monocytes promote, allergic lung inflammation in murine models of asthma. J Immunol. 2014;193(8):4245-4253.

16. Lee YG, et al. Recruited alveolar macrophages, in response to airway epithelial-derived monocyte chemoattractant protein $1 / \mathrm{CCl} 2$, regulate airway inflammation and remodeling in allergic asthma. Am J Respir Cell Mol Biol. 2015;52(6):772-784.

17. Liu T, et al. Type 2 innate lymphoid cells: a novel biomarker of eosinophilic airway inflammation in patients with mild to moderate asthma. Respir Med. 2015;109(11):1391-1396.

18. Smith SG, et al. Increased numbers of activated group 2 innate lymphoid cells in the airways of patients with severe asthma and persistent airway eosinophilia. J Allergy Clin Immunol. 2016;137(1):75-86.e8.

19. Chen R, et al. Allergen-induced increases in sputum levels of group 2 innate lymphoid cells in subjects with asthma. Am J Respir Crit Care Med. 2017;196(6):700-712.

20. Yu M, Tsai M, Tam SY, Jones C, Zehnder J, Galli SJ. Mast cells can promote the development of multiple features of chronic asthma in mice. JClin Invest. 2006;116(6):1633-1641.

21. Yu M, et al. Identification of an IFN- $\gamma /$ mast cell axis in a mouse model of chronic asthma. JClin Invest. 2011;121(8):3133-3143.

22. Heger K, et al. A2O-deficient mast cells exacerbate inflammatory responses in vivo. PLoS Biol. 2014;12(1):e1001762.

23. Peters MC, Mekonnen ZK, Yuan S, Bhakta NR, Woodruff PG, Fahy JV. Measures of gene expression in sputum cells can identify TH2-high and TH2-low subtypes of asthma. JAllergy Clin Immunol. 2014;133(2):388-394.

24. Nair P, et al. Mepolizumab for prednisone-dependent asthma with sputum eosinophilia. $N$ Engl $J$ Med. 2009;360(10):985-993.

25. Haldar P, et al. Mepolizumab and exacerbations of refractory eosinophilic asthma. N EnglJMed. 2009;360(10):973-984.

26. Pavord ID, et al. Mepolizumab for severe eosinophilic asthma (DREAM): a multicentre, double-blind, placebo-controlled trial. Lancet. 2012;380(9842):651-659.

27. Wenzel S, et al. Dupilumab in persistent asthma with elevated eosinophil levels. $N$ Engl J Med. 2013;368(26):2455-2466.

28. Peters MC, et al. Refractory airway type 2 inflammation in a large subgroup of asthmatic patients treated with inhaled corticosteroids. J Allergy Clin
Immunol. 2019;143(1):104-113.e14.

29. Berry M, et al. Pathological features and inhaled corticosteroid response of eosinophilic and non-eosinophilic asthma. Thorax. 2007;62(12):1043-1049.

30. McGrath KW, et al. A large subgroup of mild-to-moderate asthma is persistently noneosinophilic. Am J Respir Crit Care Med. 2012;185(6):612-619.

31. Hsia CC, Hyde DM, Ochs M, Weibel ER, ATS/ ERS Joint Task Force on Quantitative Assessment of Lung Structure. An official research policy statement of the American Thoracic Society/European Respiratory Society: standards for quantitative assessment of lung structure. Am J Respir Crit Care Med. 2010;181(4):394-418.

32. Woodruff PG, Innes AL. Quantitative morphology using bronchial biopsies. European Respiratory Review. 2006;15(101):157-161.

33. Neill DR, et al. Nuocytes represent a new innate effector leukocyte that mediates type-2 immunity. Nature. 2010;464(7293):1367-1370.

34. Price AE, et al. Systemically dispersed innate IL-13-expressing cells in type 2 immunity. Proc Natl Acad Sci U S A. 2010;107(25):11489-11494.

35. Moro K, et al. Innate production of $\mathrm{T}(\mathrm{H}) 2$ cytokines by adipose tissue-associated c-Kit(+)Sca-1(+) lymphoid cells. Nature. 2010;463(7280):540-544.

36. Kirshenbaum AS, et al. Characterization of novel stem cell factor responsive human mast cell lines LAD 1 and 2 established from a patient with mast cell sarcoma/leukemia; activation following aggregation of FcepsilonRI or FcgammaRI. Leuk Res. 2003;27(8):677-682.

37. Laidlaw TM, et al. Characterization of a novel human mast cell line that responds to stem cell factor and expresses functional Fc\&RI. J Allergy Clin Immunol. 2011;127(3):815-22.e1.

38. Chu DK, et al. IL-33, but not thymic stromal lymphopoietin or IL-25, is central to mite and peanut allergic sensitization. JAllergy Clin Immunol.2013;131(1):187-200.e1.

39. Willart MA, et al. Interleukin-1 $\alpha$ controls allergic sensitization to inhaled house dust mite via the epithelial release of GM-CSF and IL-33. J Exp Med. 2012;209(8):1505-1517.

40. Kouzaki H, Iijima K, Kobayashi T, O'Grady SM, Kita H. The danger signal, extracellular ATP, is a sensor for an airborne allergen and triggers IL-33 release and innate Th2-type responses. JImmunol. 2011;186(7):4375-4387.

41. Hsu CL, Neilsen CV, Bryce PJ. IL-33 is produced by mast cells and regulates IgE-dependent inflammation. PLoS One. 2010;5(8):e11944.

42. Nagarkar DR, et al. IL-13 mediates IL-33-dependent mast cell and type 2 innate lymphoid cell effects on bronchial epithelial cells. J Allergy Clin Immunol. 2015;136(1):202-205.

43. Ho JE, et al. Common genetic variation at the IL1RL1 locus regulates IL-33/ST2 signaling. J Clin Invest. 2013;123(10):4208-4218.

44. Gordon ED, et al. Alternative splicing of interleukin-33 and type 2 inflammation in asthma. Proc Natl Acad Sci U S A. 2016;113(31):8765-8770.

45. Préfontaine D, et al. Increased IL-33 expression by epithelial cells in bronchial asthma. J Allergy Clin Immunol. 2010;125(3):752-754.
46. Anderson SD. Indirect challenge tests: Airway hyperresponsiveness in asthma: its measurement and clinical significance. Chest. 2010;138(2 suppl):25S-30S.

47. Robinson DS, et al. Predominant TH2-like bronchoalveolar T-lymphocyte population in atopic asthma. N Engl JMed.1992;326(5):298-304.

48. Grünig G, et al. Requirement for IL-13 independently of IL-4 in experimental asthma. Science. 1998;282(5397):2261-2263.

49. Mjösberg JM, et al. Human IL-25- and IL-33responsive type 2 innate lymphoid cells are defined by expression of CRTH2 and CD161. Nat Immunol. 2011;12(11):1055-1062.

50. Brightling CE, Bradding P, Symon FA, Holgate ST, Wardlaw AJ, Pavord ID. Mast-cell infiltration of airway smooth muscle in asthma. N Engl J Med. 2002;346(22):1699-1705.

51. Ho LH, et al. IL-33 induces IL-13 production by mouse mast cells independently of IgE-FcepsilonRI signals. JLeukoc Biol. 2007;82(6):1481-1490.

52. Iikura M, et al. IL-33 can promote survival, adhesion and cytokine production in human mast cells. Lab Invest. 2007;87(10):971-978.

53. Kaur D, et al. IL-33 drives airway hyperresponsiveness through IL-13-mediated mast cell: airway smooth muscle crosstalk. Allergy. 2015;70(5):556-567.

54. Dougherty RH, et al. Accumulation of intraepithelial mast cells with a unique protease phenotype in $\mathrm{T}(\mathrm{H}) 2$-high asthma. J Allergy Clin Immunol. 2010;125(5):1046-1053.e8.

55. Hallstrand TS, Moody MW, Wurfel MM, Schwartz LB, Henderson WR, Aitken ML. Inflammatory basis of exercise-induced bronchoconstriction. Am J Respir Crit Care Med. 2005;172(6):679-686.

56. Parsons JP, et al. An official American Thoracic Society clinical practice guideline: exerciseinduced bronchoconstriction. Am J Respir Crit Care Med. 2013;187(9):1016-1027.

57. Wilson SJ, et al. Severe asthma exists despite suppressed tissue inflammation: findings of the U-BIOPRED study. Eur Respir J. 2016;48(5):1307-1319.

58. Balzar S, et al. Mast cell phenotype, location, and activation in severe asthma. Data from the Severe Asthma Research Program. Am J Respir Crit Care Med. 2011;183(3):299-309.

59. Irani AM, Goldstein SM, Wintroub BU, Bradford T, Schwartz LB. Human mast cell carboxypeptidase. Selective localization to MCTC cells. Jimmunol. 1991;147(1):247-253.

60. Ochi H, Hirani WM, Yuan Q, Friend DS, Austen KF, Boyce JA. T helper cell type 2 cytokinemediated comitogenic responses and CCR3 expression during differentiation of human mast cells in vitro. J Exp Med. 1999;190(2):267-280.

61. Lüthi AU, et al. Suppression of interleukin-33 bioactivity through proteolysis by apoptotic caspases. Immunity. 2009;31(1):84-98.

62. Lefrançais E, et al. Central domain of IL-33 is cleaved by mast cell proteases for potent activation of group-2 innate lymphoid cells. Proc Natl Acad Sci U S A. 2014;111(43):15502-15507.

63. Waern I, Lundequist A, Pejler G, Wernersson S. Mast cell chymase modulates IL-33 levels and controls allergic sensitization in dust-mite induced airway inflammation. Mucosal Immunol. 
2013;6(5):911-920.

64. Roy A, et al. Mast cell chymase degrades the alarmins heat shock protein 70, biglycan, HMGB1, and interleukin-33 (IL-33) and limits danger-induced inflammation. J Biol Chem. 2014;289(1):237-250.

65. Shimokawa C, et al. Mast cells are crucial for induction of group 2 innate lymphoid cells and clearance of helminth infections. Immunity. 2017;46(5):863-874.e4.

66. Grützkau A, et al. Synthesis, storage, and release of vascular endothelial growth factor/vascular permeability factor (VEGF/VPF) by human mast cells: implications for the biological significance of VEGF206. Mol Biol Cell. 1998;9(4):875-884.

67. Guma M, et al. JNK1 controls mast cell degranulation and IL-1 $\beta$ production in inflammatory arthritis. Proc Natl Acad Sci U S A. 2010;107(51):22122-22127.

68. Traister RS, Uvalle CE, Hawkins GA, Meyers DA, Bleecker ER, Wenzel SE. Phenotypic and genotypic association of epithelial IL1RL1 to human TH2-like asthma. J Allergy Clin Immunol. 2015;135(1):92-99.

69. Hackett NR, et al. The human airway epithelial basal cell transcriptome. PLoS One. 2011;6(5):e18378.

70. Warner SM, et al. Transcription factor p63 regulates key genes and wound repair in human airway epithelial basal cells. Am J Respir Cell Mol Biol. 2013;49(6):978-988.

71. Weiler JM, et al. Exercise-induced bronchoconstriction update-2016. JAllergy Clin Immunol. 2016;138(5):1292-1295.e36.

72. Busse WW, et al. Investigative bronchoprovocation and bronchoscopy in airway diseases. Am J Respir Crit Care Med. 2005;172(7):807-816.

73. Dhanasekaran S, Doherty TM, Kenneth J, TB Trials Study Group. Comparison of different standards for real-time PCR-based absolute quantification. JImmunol Methods. 2010;354(1-2):34-39.

74. Hsieh FH, Lam BK, Penrose JF, Austen KF, Boyce JA. T helper cell type 2 cytokines coordinately regulate immunoglobulin E-dependent cysteinyl leukotriene production by human cord bloodderived mast cells: profound induction of leukotriene C(4) synthase expression by interleukin 4 . JExp Med. 2001;193(1):123-133.

75. Fulcher ML, Gabriel S, Burns KA, Yankaskas JR, Randell SH. Well-differentiated human airway epithelial cell cultures. Methods Mol Med. 2005;107:183-206.

76. Lane C, Burgess S, Kicic A, Knight D, Stick S. The use of non-bronchoscopic brushings to study the paediatric airway. Respir Res. 2005;6:53.

77. Lopez-Guisa JM, Powers C, File D, Cochrane E, Jimenez N, Debley JS. Airway epithelial cells from asthmatic children differentially express proremodeling factors. J Allergy Clin Immunol. 2012;129(4):990-997.e6.

78. Dweik RA, et al. An official ATS clinical practice guideline: interpretation of exhaled nitric oxide levels (FENO) for clinical applications. Am J Respir Crit Care Med. 2011;184(5):602-615. 